\title{
TINGKAT PENGETAHUAN AKAN MEMPENGARUHI TINGKAT DEPRESI PENDERITA KANKER
}

\author{
Nilamsari*, Nanik Handayani** \\ UNUSA, FKK, Prodi SI Keperawatan - Jl. Smea 57 Surabaya \\ Email : nanikhandayani.unusa.ac.id
}

\begin{abstract}
Now, cervical cancer still becomes a reproductive health problem for the females in Indonesia. Cancer diagnosis is one of the stressors which may trigger the mental problems; the common problems which often occur are anxiety and depression Therefore, the purpose of this study was to find out the correlation between cervical cancer and depression level in cervical cancer sufferers found in Indonesian Cancer Foundation, located in Surabaya The type of study was analytic-observational done by applying cross sectional approach. The population involved all women suffering from cervical cancer found in Indonesian Cancer Foundation, totally 20 people. 19 respondents fulfilling the criteria were taken as the samples by using simple random sampling technique. The instrument for collecting the data was the questionnaire of Back Depression Inventory. The data obtained before were analyzed by using Spearman's Rank correlation test with the significance level $\alpha$ $=0.05$. The result of study done to 19 respondents suffering from cervical cancer showed that half of them (47.4\%) had a low level of knowledge about cervical cancer; and $44.4 \%$ had mild depression. Moreover, according to Spearman's Rank correlation test, $p=0.024<\alpha=$ 0.05 so that $H_{0}$ was rejected describing that there was a correlation between cervical cancer and depression level in cervical cancer sufferers. The resume of this study was almost helf respondents in Indonesian Cancer Foundation had a low level of knowledge, and had mild depression. There fore the health workers was hoped usually to give informative support such as education, promotion even conseling to cervical cancer sufferers.
\end{abstract}

ABSTRAK : Saat ini kanker serviks masih merupakan masalah kesehatan perempuan di Indonesia. Diagnosa kanker merupakan salah satu stressor yang dapat memicu terjadinya gangguan kejiwaan dan yang sering muncul adalah anxietas dan depresi. Penelitian ini betujuan untuk mengetahui hubungan antara tingkat pengetahuan tentang kanker serviks dengan tingkat depresi pada penderita kanker serviks di Yayasan Kanker Indonesia Surabaya. Jenis penelitian ini adalah analitik observasional dengan pendekatan cross sectional. Populasinya yaitu seluruh wanita penderita kanker serviks di Yayasan Kanker Indonesia Surabaya yaitu 20 orang. Sampel sebanyak 19 responden yang sesuai dengan kriteria, diambil menggunakan metode simple random sampling. dengan instrument berupa kuesioner Back Depression Inventory. Data yang diperoleh diuji menggunakan Rank Spearman dengan derajat kemaknaan $\alpha=0,05$. Hasil penelitian dari 19 responden yang menderita kanker serviks, hampir setengah dari responden $(47,4 \%)$ mempunyai tingkat pengetahuan kurang dan $(44,4 \%)$ mengalami depresi ringan. Berdasarkan uji korelasi Rank Spearman, didapatkan $\rho=$ $0,024<\alpha=0,05$ sehingga $\mathrm{H}_{0}$ ditolak artinya ada hubungan antara tingkat pengetahuan tentang kanker serviks dengan tingkat depresi pada penderita kanker serviks. Simpulan dari penelitian ini adalah hampir setengahnya responden di Yayasan Kanker Indonesia Surabaya mempunyai pengetahuan yang kurang, dan mengalami depresi ringan. Untuk itu diharapkan tenaga kesehatan selalu memberikan dukungan informatif berupa edukasi, promosi maupun penyuluhan kepada penderita kanker serviks.

Kata kunci : Tingkat Pengetahuan, Kanker Serviks, Tingkat Depresi 


\section{PENDAHULUAN}

Kanker merupakan salah satu penyakit yang mematikan. Banyak kasus baru yang ditemukan, akan tetapi jenis kasus kanker yang paling tinggi di kalangan perempuan adalah kanker serviks, atau disebut juga dengan kanker leher rahim. Saat ini kanker leher rahim masih merupakan masalah kesehatan perempuan di Indonesia. Hal itu dibuktikan dengan angka kejadian dan angka kematiannya yang tinggi oleh penderita kanker ini. Diagnosa kanker merupakan salah satu stressor yang dapat memicu terjadinya gangguan kejiwaan. Gangguan yang paling sering muncul akibat diagnosa kanker adalah anxietas dan depresi. Depresi merupakan salah satu gangguan mood, dimana terjadi perubahan kondisi emosional, motivasi, fungsi dan perilaku motorik, serta kognitif pada diri seseorang (Nevid, 2005 dalam Tama, 2009).

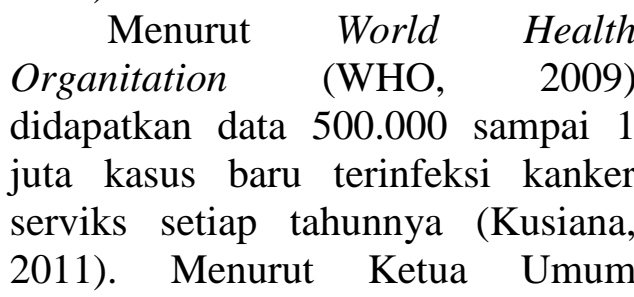
Fatayat NU Ida Fauziah di Indonesia, setiap tahun terdeteksi lebih dari 15.000 kasus kanker serviks. Sekitar 8.000 kasus di antaranya berakhir dengan kematian (Saifullah, 2012).

Berdasarkan data dari distribusi penyakit kanker di Jawa Timur pada tahun 2009 terdapat 671 orang yang mengidap kanker serviks, tahun 2010 terdapat 868 orang yang mengidap kanker serviks, tahun 2011 terdapat 1.028 orang yang mengidap kanker serviks dan terus meningkat menjadi
1.224 orang pada tahun 2012 (Dinkes Jatimprov, 2012).

Data di Yayasan Kanker Indonesia (YKI) penderita kanker serviks tahun 2012 sebesar 51 orang dan meningkat sebesar 60 orang pada tahun 2013 (YKI, 2013). Laporan ini menunjukkan bahwa ada peningkatan jumlah penderita kanker serviks tiap tahunnya. Hal itu menyebabkan kanker serviks menjadi posisi pertama di Jawa Timur. Oleh karena itu kanker serviks merupakan masalah yang umum ditakuti kaum wanita.

Nevid (2005) mengatakan prevalensi terjadinya gangguan psikiatri pada pasien kanker bervariasi antara 5 sampai $50 \%$, dengan gangguan depresi 0 sampai $46 \%$ dan gangguan anxietas sampai 49\%. Prevalensi anxietas menurun dari tahun ke tahun, tetapi tidak ada penurunan yang signifikan untuk depresi (Tama, 2009). Massie (2004) mengungkapkan bahwa setiap tahunnya terdapat 121 juta orang yang mengalami depresi (Tama, 2009). WHO menempatkannya sebagai salah satu masalah kesehatan yang amat penting di dunia. Prevalensi seumur hidup depresi pada masyarakat mencapai 5\% sampai $12 \%$ pada pria, dan $10 \%$ sampai $25 \%$ pada wanita. (Tama, 2009)

Salah satu dampak depresi pada pasien kanker adalah keinginan untuk bunuh diri. Depresi mayor berkontribusi pada sekitar 20\% hingga $35 \%$ dari kematian akibat bunuh diri di Amerika Serikat (Nevid, 2005 dalam Tama, 2009).

Depresi bukan hanya dapat menyebabkan gangguan emosional, tetapi juga dapat memperlambat 
penyembuhan pasien, iuran pengobatan yang semakin bertambah, dan akhirnya mengurangi kualitas hidup. Maka dari itu, dibutuhkan peranan seorang perawat dalam memotivasi dan memberikan asuhan keperawatan pada pasien kanker servik untuk meningkatkan kualitas hidup pasien. Kemudian diharapkan perawat juga melakukan transfer pengetahuan terhadap masyarakat dengan memberikan penyuluhan maupun health education, agar lebih paham mengenai kanker serviks sehingga masyarakat bisa mencegah teradinya kanker serviks dan mengurangi tingkat depresi yang dialami.

Selain peranan perawat, diperlukan juga peranan dari anggota keluarga yang terdekat untuk kestabilan emosi dan kesejahteraan fisik pada pasien kanker. Dukungan, perhatian dan kesabaran anggota keluarga dapat membantu penderita bersama - sama melewati masa sulitnya (Aldiansyah, 2008).

\section{METODE}

Desain yang digunakan dalam penelitian ini adalah analitik observasional, karena penelitian ini bertujuan menguji hipotesis, mengenai hubungan antar variabel. Sedangkan pendekatan yang digunakan adalah cross sectional.

Populasi dalam penelitian ini adalah seluruh wanita penderita kanker serviks di Yayasan Kanker Indonesia Surabaya dengan populasi sebesar 20 orang dalam 3 bulan terakhir yaitu Oktober, November, Desember 2013. Sampel yang digunakan dalam penelitian ini adalah sebagian wanita penderita kanker serviks di Yayasan Kanker
Indonesia Surabaya. besar sampel yang digunakan dalam penelitian ini sebanyak 19 responden wanita penderita kanker serviks di Yayasan Kanker Indonesia Surabaya. Pengambilan sampel pada penelitian ini menggunakan Probability Sampling dengan metode Simple Random sampling.

Variabel independen penelitian adalah tingkat pengetahuan tentang kanker serviks. Variabel dependen adalah tingkat depresi pada penderita kanker serviks. Instrumen yang digunakan dalam penelitian ini, untuk data variabel independen menggunakan kuesioner pengetahuan sedangkan untuk data variabel dependen menggunakan kuesioner BDI (Back's Depression Inventory). Pengumpulan data dalam penelitian ini melalui prosedur : Pengumpulan data dimulai dari pengajuan izin penelitian dari UNUSA, kemudian peneliti meminta izin kepada pimpinan Yayasan Kanker Indonesia untuk melakukan penelitian di YKI Surabaya. setelah mendapatkan izin, peneliti membuat kontrak dengan pimpinan kapan akan dilakukan penelitian di YKI yang dilaksanakan mulai bulan Maret sampai April 2014. Kemudian peneliti mengadakan pendekatan pada responden serta menjelaskan maksud dan tujuan. Sebelumnya peneliti membuat daftar nama sejumlah 20 orang kemudian nama tersebut dimasukkan dalam suatu tempat untuk diundi. Nama yang keluar pertama yaitu responden yang tidak diteliti, sisanya yaitu yang menjadi responden. Setelah itu responden yang sudah terpilih diminta untuk menandatangani lembar persetujuan menjadi 
responden. Peneliti membagikan lembar kuesioner dan diminta responden untuk menjawab pertanyaan serta menjelaskan cara pengisiannya. Selama pengisian peneliti mendampingi responden dan juga membantu memberi penjelasan apabila responden kurang memahami isi dari kuesioner. Setelah seluruh kuesioner selesai diisi, peneliti mengumpulkan seluruh kuesioner. Setelah data terkumpul dari responden dilakukan pengolahan data dengan cara sebagai berikut : Pengeditan data (Editing), memberikan skor (Scoring), memberikan kode (Coding), memasukkan data (Processing), Tabulasi data (Tabulasi), membersihkan data (Cleaning). Sesuai dengan tujuan penelitian ini maka analisa data dengan menggunakan program SPSS dan uji statistik Rank-Spearman untuk melihat adanya hubungan antara tingkat pengetahuan tentang kanker serviks dengan tingkat depresi pada penderita kanker serviks dengan tingkat kemaknaan $\alpha=0,05$. Hasil uji statistik Rank-Spearman $\mathrm{H}_{0}$ ditolak apabila $\rho<0,05$, artinya ada hubungan antara tingkat pengetahuan tentang kanker serviks dengan tingkat depresi pada penderita kanker serviks.

\section{HASIL}

Tabel 5.4 Distribusi frekuensi responden berdasarkan tingkat pengetahuan di Yayasan Kanker Indonesia Surabaya pada bulan Maret 2014

\begin{tabular}{cccc}
\hline $\begin{array}{c}\text { N } \\
\text { o }\end{array}$ & Pengetahun & Frekuensi & $\begin{array}{c}\text { Persen } \\
\operatorname{tase}(\%)\end{array}$ \\
\hline 1 & Baik & 4 & 21,1 \\
2 & Cukup & 6 & 31,6 \\
3 & Kurang & 9 & 47,4 \\
\hline & Jumlah & 19 & 100 \\
\hline
\end{tabular}

Sumber : Data primer, Maret 2014

Tabel 5.5 Distribusi frekuensi responden berdasarkan tingkat depresi di Yayasan Kanker Indonesia Surabaya pada bulan Maret 2014

\begin{tabular}{cccc}
\hline No & Tingkat Depresi & Frekuensi & Persentase (\%) \\
\hline 1 & Tidak Depresi & 2 & 10,5 \\
2 & Depresi Ringan & 7 & 36,8 \\
3 & Depresi Sedang & 6 & 31,6 \\
4 & Depresi Berat & 4 & 21,1 \\
\hline & Jumlah & 19 & 100
\end{tabular}

Sumber : Data primer, 2014 
Tabel 5.6 Tabulasi silang hubungan tingkat pengetahuan dengan tingkat depresi pada penderita kanker serviks di Yayasan Kanker Indonesia Surabaya pada bulan Maret 2014

\begin{tabular}{cccccc}
\hline \multirow{2}{*}{$\begin{array}{c}\text { Tingkat } \\
\text { Pengetahuan }\end{array}$} & Depresi Berat & Depresi Sedang & $\begin{array}{c}\text { Depresi } \\
\text { Ringan }\end{array}$ & $\begin{array}{c}\text { Tidak } \\
\text { Depresi }\end{array}$ & Jumlah \\
\cline { 2 - 5 } & $2(50,0 \%)$ & $1(25,0 \%)$ & $1(25,0 \%)$ & $0(0,0 \%)$ & $4(100 \%)$ \\
Baik & $2(33,3 \%)$ & $2(33,3 \%)$ & $2(33,3 \%)$ & $0(0,0 \%)$ & $6(100 \%)$ \\
Cukup & $0(0,0 \%)$ & $3(33,3 \%)$ & $4(44,4 \%)$ & $2(22,2 \%)$ & $9(100 \%)$ \\
Kurang & $4(21,1 \%)$ & $6(31,6 \%)$ & $7(36,8 \%)$ & $2(10,5 \%)$ & $19(100 \%)$ \\
\hline Jumlah & & & &
\end{tabular}

Sumber : Data Primer, Maret 2014

\section{PEMBAHASAN}

Berdasarkan tabel 5.4 menunjukkan bahwa dari 19 responden hampir setengahnya $(47,4 \%)$ dari responden mempunyai pengetahuan yang kurang. Hasil penelitian, diketahui bahwa jawaban kuesioner yang terisi pada item soal 1 - 10 tentang pengetahuan, soal multiple choice tingkat pengetahuan tentang tanda gejala, penyebab, dan faktor resiko terjadinya kanker serviks responden menjawab pertanyaan dengan jawaban yang salah, yaitu responden tidak dapat menjawab pertanyaan dengan benar apa tanda gejala, penyebab dan faktor resiko terjadinya kanker serviks. Pengetahuan umumnya datang dari pegalaman juga didapat dari informasi yang disampaikan oleh orang lain, buku, surat kabar, elektronik atau media massa (Notoadmodjo, 2003). Pada kenyataan dilapangan pengetahuan responden yang kurang ini disebabkan karena keterbatasan tempat, waktu serta cara. Banyak responden yang tinggal di desa hal ini memungkinkan tidak adanya media cetak berupa koran atau buku tentang kanker seviks, dan rata - rata pekerjaan responden adalah petani, jadi pengetahuan yang lebih di ketahui tentang bercocok tanam.

Berdasarkan tabel 5.5 menunjukkan dari 19 responden hampir setengah $(36,8 \%)$ mengalami depresi ringan. Menurut L Philips (1992) dalam (Pieter dkk, 2001) menyatakan bahwa depresi adalah gangguan perasaan, kondisi emosional yang berkepanjangan yang mewarnai seseorang mengalami gangguan berpikir, perilaku dan perasaan tidak berdaya serta merasa hilangnya harapan.

Hasil penelitian ini sesuai dengan penelitian sebelumnya yang menyebutkan tingkat depresi terbanyak adalah depresi ringan (23\%) (Permatahati, 2005). Menurut Tama (2009) depresi dengan proporsi terbanyak adalah tingkat depresi ringan (21\%). Sedangkan tingkat depresi terbanyak adalah depresi sedang $(37,3)$, menurut hasil pnelitian (Aldiansyah, 2008). Perbedaan hasil penelitian ini bisa dipengaruhi oleh perbedaan skala depresi yang dipakai dan lokasi penelitian yang diambil, dimana peneliti memakai skala Back Depression Inventory (BDI) untuk menilai keparahan depresi responden. 
Depresi melibatkan berbagai faktor yang saling mempengaruhi. Depresi dapat merefleksikan interaksi antara faktor pengetahuan, umur, faktor biologis, faktor psikologis, serta stressor sosial dan lingkungan. Pengetahuan yang diberikan seseorang pada orang lain terhadap suatu hal agar mereka dapat memahami. Semakin tinggi pengetahuan seseorang semakin mudah menerima informasi dan semakin banyak pengetahuan yang dimiliki. Sebaliknya jika seseorang tingkat pengetahuannya rendah, akan menghambat perkembangan sikap seseorang terhadap penerimaan, informasi dan nilai - nilai yang baru diperkenalkan sehinga rentan terjadi depresi (Lubis N, 2009). Dilihat dari fakta yang ada dilapangan responden yang mengalami depresi ringan tersebut mempunyai pengetahuan yang rendah diakibatkan rata - rata pendidikan yang ditempuh adalah pendidikan menengah. Hal tersebut sudah sesuai dengan teori di atas.

Pada tabel 5.6 menunjukkan bahwa 19 responden dalam penelitian dari 4 ibu yang mempunyai tingkat pengetahuan baik setengah dari responden $(50,0 \%)$ mengalami depresi berat. Sedangkan ibu yang mempunyai tingkat pengetahuan cukup yang berjumlah 6 orang dan tidak satupun dari responden $(0,0 \%)$ yakni 0 orang yang tidak mengalami depresi. Pada ibu yang mempunyai tingkat pengetahuan kurang berjumlah 9 orang dan hampir setengah dari responden $(44,4 \%)$ yakni 4 orang mengalami depresi ringan.

Masa dewasa adalah periode yang paling penting dalam masa khidupan, masa ini dibagi dalam 3 periode yaitu: Masa dewasa awal, Masa dewasa pertengahan, dan masa akhir atau usia lanjut. Masa Dewasa madya / dewasa pertengahan ini berlangsung dari umur 40 - 60 tahun. Menurut Erikson, selama usia madya ini orang akan menjadi lebih sukses atau sebaliknya mereka berhenti (stagnasi), Pada masa dewasa pertengahan ini perhatian terhadap agama lebih besar dibandingkan dengan masa sebelumnya, dan kadang-kadang minat dan perhatiannya terhadap agama ini dilandasi kebutuhan pribadi dan sosial (Yusuf LN, 2006).

Pada dasarnya ibu yang mempunyai pengetahuan yang kurang akan mengakibatkan depresi berat. Akan tetapi fakta pda lapangan berbanding terbalik dengan teori yang ada. Hasil penelitian tersebut dapat dilihat dari segi umur pada responden Ny. S yang berumur 73 tahun dan Ny. J 70 tahun (dewasa pertengahan). Jadi, faktor umur dapat mempengaruhi tingkat depresi seseorang dikarenakan pada usia pertengahan ini perhatian terhadap agama lebih besar dibandingkan dengan masa sebelumnya, sehingga responden menerima dengan keadaan penyakit yang dideritanya. Selain itu bisa dilihat dari 5 tahapan seseorang yang kehilangan, yaitu marah, menolak, tawar menawar,depresi dan menerima. Kemungkinan responden yang ada di YKI sudah mengidap kanker seviks dalam waktu yang lama dan sudah melewati tahap depresi, dan pada saat dilakukan penelitian responden tersebut sudah pada tahap yang terakhir yaitu menerima. 


\section{SIMPULAN}

Setelah dilakukan penelitian di Yayasan Kanker Indonesia Surabaya tentang tingkat pengetahuan tentang kanker serviks dengan tingkat depresi pada penderita kanker serviks didapatkan : Penderita kanker serviks di Yayasan Kanker Indonesia Surabaya hampir setengahnya mempunyai pengetahuan yang kurang, Penderita kanker serviks di Yayasan Kanker Indonesia Surabaya hampir setengahnya mengalami depresi ringan, Tingkat pengetahuan tentang kanker serviks ada hubungan dengan tingkat depresi pada penderita kanker serviks di Yayasan Kanker Indonesia Surabaya.

\section{DAFTAR PUSTAKA}

Aldiansyah, Dudy. 2008. Tingkat Depresi Pada Pasien Kanker Serviks Uteri Di RSUPHAM dan RSUPM Dengan Menggunakan Skala Beck Depression Inventory - II. Universitas Sumatra Utara. Skripsi. Diakses dalam http://library.usu.ac.id/. Pada tanggal 17 November 2013

Alimul Aziz, 2003. Metode penelitian keperawatan teknik analisa data. Jakarta: Salemba Media

Aspuah, Siti. 2013. Kumpulan Kuesioner dan Instrumen Penelitian Kesehatan. Jakarta : Medical Book

Budiman, Riyanto \& Agus. 2013. Pengetahuan dan Sikap dalam Penelitian Kesehatan. Jakarta: Salemba Medika

Diananda, Rama. 2008. Mengenal Seluk Beluk Kanker. Yogyakarta : Kata Hati
Dinkes Pemprov. 2012. Kegiatan Pengendalian Kanker di Jawa Timur. Diakses dalam http://dinkes.jatimprov.go.id/. Pada tanggal 12 Desember 2013

Hawari, Dadang. 2009. Psikometri Alat Ukur (Skala) Kesehatan Jiwa. Jakarta : Fakultas Kedokteran Universitas Indonesia

Herschbach,P. 2004. Pscycological Problems of Cancer Patients: A Cancer Distress Screening With A Cancer Specific Questionnaier. British Jounal of Cancer (91). Diakses dalam

http://www.nature.com/bjc/jo urnal/v91/n3/full/6601986a.ht ml. Diakses pada tanggal 12 Desember 2013

Nursalam.2002. Konsep dan Penerapan Metodologi Penelitian Ilmu

Keperaawatan. Jakarta: Salemba Medika

Ngatimin. 2004. Pengertian Pengetahuan Menurut Para Ahli. Jakarta: Salemba 